\title{
Ways to Greater Happiness: A Delphi Study
}

\author{
Dan Buettner ${ }^{1} \cdot$ Toben Nelson $^{2} \cdot$ Ruut Veenhoven $^{3,4}$ (D)
}

Published online: 5 February 2020

(c) The Author(s) 2020

\begin{abstract}
In the first round of this Delphi study 14 experts suggested strategies for improving life-satisfaction. In a second round, experts rated these strategies for (a) effectiveness, (b) feasibility and (c) cost-effectiveness. They considered 56 strategies policy makers can use to raise average happiness in a nation and 68 ways in which individuals can raise their own happiness. Experts were informed about the average ratings made by the panel and about the arguments advanced. Then, in a third round, experts made their final judgments. Summed ratings for average effectiveness and feasibility of the strategies ranged between 8.4 and 4.9 on scale $2-10$, which means that most of the recommendations were deemed suitable. Agreement was slightly higher on policy strategies than on individual ways to greater happiness. Policy strategies deemed the most effective and feasible are: (1) investing in happiness research, (2) support of vulnerable people and (3) improving the social climate, in particular by promoting voluntary work and supporting non-profits. Individual strategies deemed most effective are: (a) investing in social networks, (b) doing meaningful things and (c) caring for one's health.
\end{abstract}

Keywords Life-satisfaction $\cdot$ Research review $\cdot$ Policy advice $\cdot$ Utilitarianism

This study was commissioned by National Geographic Inc, Washington USA.

A more detailed report of this study is available at https://www.eur.nl/en/ehero/publications/worki ng-papers/2017-01. From this site you can download: 1) A pdf version of this paper which involves links from the text to rows in tables, 2) Excel files for the tables 2 and 3 in which you can sort, 3) Documentation about this Delphi study, and 4) A copy of the data set.

Ruut Veenhoven

veenhoven@ese.eur.nl

Gallup, Washington, USA

2 Division of Epidemiology and Community Health, University of Minnesota, Minneapolis, USA

3 Erasmus Happiness Economics Research Organization, Erasmus University Rotterdam, Rotterdam, The Netherlands

4 Opentia Research Program, North-West University South Africa, Vanderbijlpark, South Africa 


\section{Introduction}

\subsection{Call for Greater Happiness}

All humans want a satisfying life for themselves and their children. This is seen in the high ranking given to happiness in the value hierarchies of students all over the world (Diener et al. 1995) and in the preferences of ordinary people in western nations (e.g. Adler et al. Adler et al. 2015). Individually, people seek ways to achieve a more satisfying life and this quest is manifests in the soaring sales of 'how-to-be-happy' books and in the ongoing development of life-coaching businesses. Citizens in western societies call on their governments to improve the social conditions for happiness; for example, $85 \%$ of the British agree with the statement that 'A governments prime aim should be achieving the greatest happiness of the people, not the greatest wealth' (BBC 2006, question 14).

This call for greater happiness is not new, it has figured in western thought since antiquity and became particularly salient in the eighteenth century European Enlightenment, a spokesman of which was Jeremy Bentham, who declared that we should aim at 'greater happiness for a greater number' (Bentham 1789). This call for greater happiness gains strength these days, among other things because research has shown that greater happiness is possible (Veenhoven 2015).

\subsection{Happiness Research}

Over the ages the subject of happiness has been a subject of philosophical speculation but in the second half of the twentieth century it also became of subject of empirical research. In the 1950s, happiness appeared as a side-topic in research on successful aging and mental health. In the 1970s happiness became a main topic in social indicators research and since 2000, it has become the main subject of the field of Happiness Economics. All this research is gathered in the World Database of Happiness (Veenhoven 2017a, b, c) To date (October 2017), this findings-archive covers the work of some 15,000 investigators, who have produced about 30,000 research findings, both findings on how happy people are (distributional findings) and findings on things that go together with more or less happiness (correlational findings).

The available research findings show that a high degree of happiness is possible. In answer to a question on how much they like the life they live, many people tick the highest possible response option, such as 'very happy' and in Denmark the average score on a numerical scale $0-10$ is 8.4. Correlational findings give cues about conditions for happiness, both with respect to the kind of society in which people life happiest and to differences in individual ways of life between more and less happy people.

\subsection{Inference of Recommendations}

These data are typically gathered with the purpose of identifying ways to greater happiness, both for policy makers and individuals. Yet deriving recommendations is not easy. Correlations do not always denote causes and effects on happiness can differ across persons and situations. Hence, reading the available research data requires specialized expertise. Expertise is also required to judge the practical feasibility of strategies to raise happiness.

There is a growing literature on ways to greater happiness. Scientific publications on this subject are listed in the Bibliography of Happiness (Veenhoven 2017c), which currently 
holds 282 publications on policy implications of happiness research ${ }^{1}$ and 217 publications on observed effects of individual level interventions, ${ }^{2}$ such as psychological trainings. The scientific literature on what individuals themselves can do to get happier is much smaller, though there is an abundance of popular self-help literature, in which references are made to research findings.

\subsection{Problems in Getting an Overview}

The available literature on ways to greater happiness is difficult to oversee. Not only are the writings too numerous to digest for an interested layperson, but any view is limited by conceptual confusion and technical jargon. Even more problematic is that many of the recommendations are contradictory of others, or apply only in particular situations. Another problem is that the derived recommendations are often not free from ideological bias. Therefore, considerable expertise is required to make sense of the advisory literature on ways to greater happiness.

One way to get an overview of the recommendations is to do a review study, that is, to read all the available literature and consider the strengths and weakness of the various recommendations advanced, and propose a list of best ways to greater happiness. This takes a lot of time, and typically results in a book, which is then added to the pile of existing advisory literature. This approach is time-consuming and vulnerable to being skewed towards the preferences of the reviewer. An alternative way to separate to grain from the chaff among these many recommendations is to pick the brains of several experts and gather theirs views. That approach is followed in this study.

\subsection{Aim of this Study}

We want to know what ways to greater happiness are recommended by the best-informed people of our time, that is, experts in empirical happiness research. We want to know what strategies they envision, how they rank these strategies for effectiveness and feasibility and how much consensus there is among the experts.

\section{Method}

Expert-opinion was gathered using the Delphi-method. This involves structured consultation of a panel of specialists about a particular problem, typically involving several rounds, in which experts express their views and consider each other's opinions before making a final judgment. The method has been used for forecasting future developments. Here, we use it to understand the implications of present day happiness research.

\footnotetext{
${ }^{1}$ Section 'Policy implications', direct link: https://worlddatabaseofhappiness.eur.nl/hap_bib/src_pubs. php? mode $=1 \&$ Subject $=187$.

${ }^{2}$ Section 'Individual level interventions', direct link: https://worlddatabaseofhappiness.eur.nl/hap_bib/src_ pubs.php?mode $=1 \&$ Subject $=1714$.
} 


\subsection{Experts}

We invited senior scientists who have a strong record in empirical research on happiness, defined in the sense of satisfaction with one's life as-a-whole. We selected these experts from the Directory of Happiness Investigators of the World Database of Happiness (Veenhoven 2017b) with an eye on the different strands that exist in this research field. Together 20 experts were invited, of which 15 agreed to participate, 10 of these completed all the steps described below, 2 participated only in round 1 and 3 only in round two. Two of us (Buettner and Veenhoven) also participated in the Delphi process. This resulted in the following list of participants in this study.

- Dan Ariely, Duke University, USA

- Mak Arvin, Trent University, Canada

- Leonardo Becchetti, University of Roma Tor Vergata, Italy

- Dan Buettner, Independent science writer and National Geographic, USA

- Bob Cummins, Deakin University, Australia

- Johannes Echstaedt, University of Pennsylvania, USA

- Bruno Frey, University of Zurich, Switzerland

- Carol Graham, Brookings Institute, USA

- David Halpern, Behavioral Insights Team, UK

- Bruce Headey, University of Melbourne, Australia

- John Helliwell, University of British Columbia, Canada

- Richard Layard, London School of Economics, UK

- Richard Lucas, Michigan State University, USA

- Sonja Lyubomirsky \& Kristin Layous, University of California Riverside, USA

- Ruut Veenhoven, Erasmus University Rotterdam, Netherlands

- Heinz Welsch, University of Oldenburg, Germany

- Dan Witters, Gallup, USA

\subsection{Concept Life-Satisfaction}

We asked experts to focus on happiness in the sense of life-satisfaction; that is, the subjective enjoyment of one's life as a whole. Thus, we avoided the conceptual confusion that often haunts happiness advice. We reminded experts that the research literature on happiness defined in this particular sense is gathered in the World Database of Happiness.

\subsection{Questions}

We asked these experts the following two fundamental questions:

A. What policies are most likely to yield greater happiness for a greater number of citizens in nations?

B. What individual strategies are most likely to enhance people's happiness in the long run? 
Table 1 How the expert ratings were sorted

\begin{tabular}{|l|l|l|l|l|l|l|l|}
\hline \multicolumn{2}{|l|}{ Ways to greater happiness } & \multicolumn{5}{|c|}{ Rating by experts on scale 1-5 } \\
\hline category & strategy & \multicolumn{2}{|c|}{ Effectiveness } & \multicolumn{2}{c|}{ Feasibility } & \multicolumn{2}{c|}{ Cost-effectiveness } \\
\cline { 3 - 9 } & & M & SD & M & SD & M & SD \\
\hline & & & & & & & \\
\hline & & & & & & & \\
\hline & & & & & & & \\
\hline
\end{tabular}

Key to colors

\begin{tabular}{|c|c|c|c|c|c|c|}
\hline \multicolumn{3}{|c|}{ Average rating by experts (Mean) } & \multicolumn{3}{c|}{ Expert agreement (Standard Deviation) } \\
\hline Very good & Good & Average & & High & Medium high & Medium low \\
\hline
\end{tabular}

\subsection{Procedure}

The following 5-step procedure was followed:

1. We asked experts to suggest their best ideas to address each of the two questions above: what ways to follow and why.

2. We sorted the answers, eliminated redundancy and rephrased some of the suggestions.

3. We presented the resulting list of strategies to the experts, together with the justifications provided in first round. We asked them to rate each of the strategies for effectiveness, cost-effectiveness and feasibility.

4. We then presented the list obtained in step 3, consisting of strategies and initial ratings, to the experts and invited them to comment.

5. The experts then made their final rating. For this second rating, we limited to the 40 strategies on which experts had disagreed most in step 2. In this last round, the experts were also asked to consider a set of specific individual behaviors that figure in popular happiness advice. Rating of these latter strategies was optional.

\subsection{Analysis}

We counted the number of experts who had rated that recommendation for each of the proposed ways to greater happiness. We next computed the mean ratings, on a 1-5 scale, for (1) effectiveness of the strategy, (2) feasibility and (3) cost effectiveness. We also computed the standard deviation of the ratings, to get a view on rated agreement. These numbers are reported in Excel files, links to which are at the bottom of Tables 2 and 3.

We then ranked all the strategies by the sum of effectiveness and feasibility.

All rankings were classified into 4 degrees, the means into 4 degrees of effectiveness and feasibility, the standard deviation into 4 degrees of expert agreement. See Table 1 . We used standard deviations from the mean as boundaries, top and bottom quarters respectively above and below one standard deviation from the mean and the two middle categories within one standard-deviation above and below the mean. 
Table 2 Expert ratings of ways to greater happiness for a greater number of citizens (policy strategies)

\begin{tabular}{|c|c|c|c|c|c|c|c|c|}
\hline Category & Strategy & Nr. & $\begin{array}{c}\text { Sum mean } \\
\text { effectiveness } \\
+ \\
\text { feasibility }\end{array}$ & $\begin{array}{c}\text { Effectiveness } \\
+ \\
\text { Feasibility } \\
\text { SD }\end{array}$ & $\begin{array}{l}\text { Effectiveness } \\
\text { Mean }\end{array}$ & $\begin{array}{l}\text { Effectiveness } \\
\text { SD }\end{array}$ & $\begin{array}{l}\text { Feasibility } \\
\text { Mean }\end{array}$ & $\begin{array}{c}\text { Feasibility } \\
\text { SD }\end{array}$ \\
\hline $\begin{array}{l}\text { Happiness Research } \\
\text { Social Climate }\end{array}$ & Look for What Works for Whom & $10 \mathrm{c}$ & 8.5 & 1.35 & $\begin{array}{l}4.5 \\
4.3\end{array}$ & $\begin{array}{l}0.82 \\
0.67\end{array}$ & $\begin{array}{l}3.8 \\
4.0\end{array}$ & $\begin{array}{l}0.92 \\
0.67\end{array}$ \\
\hline Happiness Research & $\begin{array}{l}\text { Promote Voluntary Work. Civil Service } \\
\text { Assess How Much of the Above is Optimal }\end{array}$ & $\begin{array}{l}8 b \\
10 b\end{array}$ & $\begin{array}{l}8.3 \\
8.1\end{array}$ & $\begin{array}{l}1.25 \\
1.66\end{array}$ & 4.1 & 0.83 & 3.9 & 1.20 \\
\hline Personal Support & Reduce Loneliness & $6 b$ & 8.1 & 1.24 & 4.5 & 0.67 & 3.6 & 0.90 \\
\hline Happiness Research & Monitor Happiness in Nations & $10 a$ & 8.1 & 1.56 & 4.0 & 1.04 & 4.1 & 0.67 \\
\hline Personal Support & Focus on the Least Happy & $6 e$ & 7.8 & 1.06 & 4.4 & 0.51 & 3.3 & 0.89 \\
\hline Freedom & Combat Discrimination & $5 c$ & 7.5 & 1.08 & 4.5 & 0.71 & 3.0 & 0.94 \\
\hline Social Climate & Increase Support for Non-Profits & $8 c$ & 7.5 & 1.27 & 3.8 & 0.79 & 3.7 & 0.67 \\
\hline Freedom & Foster Freedom to Choose & $7 a b$ & 7.5 & 1.51 & 3.8 & 0.98 & 3.6 & 0.84 \\
\hline Education & Bring Life Skills to Schools & $7 a$ & 7.5 & 1.62 & 3.9 & 1.31 & 3.6 & 0.67 \\
\hline Education & Invest in Education & $5 a$ & 7.4 & 1.17 & 4.2 & 0.79 & 3.2 & 1.03 \\
\hline Environment & Support of Fairs and Festivals & $3 d$ & 7.3 & 1.56 & 3.3 & 0.97 & 4.1 & 0.79 \\
\hline Health & Encourage Healthy Living & $8 a$ & 7.3 & 1.42 & 3.6 & 1.03 & 3.6 & 0.70 \\
\hline Social Climate & Facilitate Social Contacts & $2 d$ & 7.3 & 1.60 & 3.8 & 0.87 & 3.5 & 0.90 \\
\hline Personal Support & Support Families & $7 \mathrm{~b}$ & 7.2 & 1.47 & 4.0 & 1.04 & 3.1 & 0.94 \\
\hline Freedom & Foster Ability to Choose & $4 a$ & 7.2 & 2.17 & 3.7 & 1.37 & 3.5 & 1.00 \\
\hline Governance & Promote Good Government & $6 a$ & 7.1 & 0.99 & 4.5 & 0.53 & 2.6 & 0.97 \\
\hline Economic & Improve Work Conditions & $1 \mathrm{j}$ & 7.1 & 1.76 & 4.3 & 0.97 & 2.8 & 0.87 \\
\hline Health & Prioritize Prevention & $5 d$ & 7.0 & 1.49 & 3.8 & 0.98 & 3.1 & 0.99 \\
\hline Governance & Empower and Involve Citizens & $4 d$ & 7.0 & 1.70 & 3.9 & 0.94 & 3.0 & 0.94 \\
\hline Education & Maintain Order in Schools & $2 c$ & 7.0 & 1.70 & 3.7 & 1.10 & 3.3 & 0.67 \\
\hline Governance & Be Explicit About Greater Happiness & 1f & 7.0 & 2.41 & 3.1 & 1.51 & 3.9 & 1.14 \\
\hline Economic & Provide Minimum Income Security & $1 \mathrm{e}$ & 6.9 & 1.24 & 4.2 & 0.94 & 2.8 & 0.87 \\
\hline Economic & Reduce Unemployment & $2 a$ & 6.9 & 0.83 & 3.9 & 0.90 & 3.0 & 0.77 \\
\hline Health & Provide Free Healthcare & $4 b$ & 6.9 & 1.14 & 4.5 & 0.52 & 2.5 & 1.21 \\
\hline Education & Promote Financial Education & $5 \mathrm{ca}$ & 6.9 & 1.70 & 3.2 & 0.98 & 3.7 & 0.89 \\
\hline Health & Promote Sports & $2 \mathrm{db}$ & 6.8 & 1.11 & 3.3 & 0.75 & 3.6 & 0.79 \\
\hline Health & Prioritize Mental Health Care & $2 b$ & 6.7 & 1.56 & 3.9 & 0.94 & 2.8 & 1.17 \\
\hline Personal Support & Support Happiness Education & $6 c$ & 6.7 & 2.35 & 3.2 & 1.40 & 3.5 & 1.09 \\
\hline Economic & Top-up' Wages Program & $5 f$ & 6.5 & 1.21 & 3.8 & 0.60 & 2.7 & 0.90 \\
\hline Education & Monitor Happiness in Schools & 1ea & 6.5 & 2.70 & 3.2 & 1.40 & 3.4 & 1.43 \\
\hline Environment & Invest in a Greener Environment & $3 e$ & 6.5 & 1.43 & 3.4 & 0.97 & 3.1 & 0.74 \\
\hline Environment & Limit Urban Sprawl & $3 b$ & 6.4 & 1.43 & 3.7 & 0.95 & 2.7 & 0.82 \\
\hline Education & Educate Parents & $5 g$ & 6.4 & 1.51 & 3.2 & 0.87 & 3.2 & 0.63 \\
\hline Economic & Favor Economic Stability Over Growth & $8 d$ & 6.3 & 1.06 & 3.9 & 0.32 & 2.4 & 0.97 \\
\hline Social Climate & Increase Foreign Aid & $1 \mathrm{~b}$ & 6.3 & 1.34 & 3.5 & 0.97 & 2.8 & 0.63 \\
\hline Education & Facilitate Internet Access & $2 d d$ & 6.3 & 1.01 & 2.5 & 0.52 & 3.7 & 0.65 \\
\hline Health & Promote 8 Hours of Sleep & $5 \mathrm{~h}$ & 6.3 & 1.79 & 3.3 & 1.01 & 3.0 & 1.00 \\
\hline Environment & Invest in Clean Air & $3 c$ & 6.2 & 1.14 & 3.7 & 0.95 & 2.5 & 0.53 \\
\hline Education & Provide Free Education & $5 b$ & 6.2 & 1.14 & 3.7 & 0.48 & 2.5 & 1.08 \\
\hline Economic & Favor Saving Over Consumption & 1 ha & 5.9 & 1.29 & 3.1 & 0.88 & 2.8 & 0.63 \\
\hline Health & Promote Healthy Eating & $2 \mathrm{da}$ & 5.8 & 2.08 & 2.7 & 1.07 & 3.2 & 1.19 \\
\hline Health & Get People to the Dentist & $2 \mathrm{dc}$ & 5.8 & 1.62 & 2.8 & 1.03 & 3.0 & 0.82 \\
\hline Personal Support & Improve Happiness Advise/Coaching & $6 d$ & 5.8 & 2.30 & 2.7 & 1.23 & 3.1 & 1.16 \\
\hline Economic & Support Home Ownership & $1 \mathrm{hb}$ & 5.6 & 1.43 & 2.7 & 1.01 & 2.9 & 0.54 \\
\hline Economic & Increase Taxes & $1 d$ & 5.6 & 1.44 & 3.3 & 1.14 & 2.3 & 0.65 \\
\hline Modernization & Support Ongoing Societal Modernization & $9 a$ & 5.5 & 1.29 & 2.6 & 1.03 & 2.9 & 0.70 \\
\hline Economic & Foster Economic Growth & $1 \mathrm{~g}$ & 5.5 & 1.04 & 2.5 & 0.82 & 3.0 & 1.10 \\
\hline Economic & Reduce Income Inequality & $1 \mathrm{a}$ & 5.5 & 1.21 & 3.2 & 0.98 & 2.3 & 0.65 \\
\hline Economic & Reduce Working Hours & $1 \mathrm{i}$ & 5.4 & 1.73 & 2.8 & 1.06 & 2.7 & 0.98 \\
\hline Economic & CEO Tax to reduce Income Inequality & $4 c$ & 5.3 & 1.80 & 2.8 & 1.09 & 2.6 & 0.88 \\
\hline Governance & Decentralize & $5 e$ & 5.3 & 1.42 & 2.9 & 1.31 & 2.5 & 0.82 \\
\hline Education & Facilitate Study Elsewhere & $1 \mathrm{hc}$ & 5.0 & 1.50 & 2.1 & 0.93 & 2.9 & 0.78 \\
\hline Economic & $\begin{array}{l}\text { Stimulate Consumption of Stimulus Goods } \\
\text { Over Comfort Goods }\end{array}$ & 37 & 4.8 & 1.75 & 27 & 123 & 22 & 083 \\
\hline Environment & Reduce Use of Cars & $1 \mathrm{c}$ & $\begin{array}{l}4.8 \\
4.7\end{array}$ & $\begin{array}{l}1.13 \\
1.37\end{array}$ & $\begin{array}{l}2.1 \\
2.5\end{array}$ & 0.90 & $\begin{array}{l}2.2 \\
2.2\end{array}$ & $\begin{array}{l}0.83 \\
0.83\end{array}$ \\
\hline Economic & Counterbalance Global Capitalism & $6 e$ & 4.2 & 1.81 & 2.6 & 1.43 & 1.6 & 0.70 \\
\hline Mean & & & 6.6 & 1.50 & 3.5 & 0.95 & 3.07 & 0.87 \\
\hline SD & & & 0.96 & 0.38 & 0.64 & 0.25 & 0.54 & 0.19 \\
\hline Median & & & 6.7 & 1.4 & 3.7 & 1.0 & 3.0 & 0.9 \\
\hline $\mathrm{SD}+$ & & & 7.54 & 1.88 & 4.13 & 1.20 & 3.62 & 1.06 \\
\hline SD- & & & 5.61 & 1.11 & 2.85 & 0.69 & 2.53 & 0.68 \\
\hline
\end{tabular}

An Excel file with more detail is available at: https://www.eur.nl/en/ehero/publications/working-paper s/2017-01

Using this file, you can sort the ratings in different ways

We will first discuss the general tendency in the ratings; which strategies are deemed the most appropriate and which the least? In that analysis, we focused on the means. Then, 
Table 3 Expert rating of ways to greater happiness for a person can follow (individual strategies)

\begin{tabular}{|c|c|c|c|c|c|c|c|c|}
\hline Category & Strategy & Nr. & $\begin{array}{c}\text { Sum of mean } \\
\text { effectiveness } \\
+ \\
\text { feasibility }\end{array}$ & $\begin{array}{c}\text { Effectiveness } \\
+ \\
\text { Feasibility } \\
\text { SD }\end{array}$ & $\begin{array}{c}\text { Effectiveness } \\
\text { Mean }\end{array}$ & $\begin{array}{c}\text { Effectiveness } \\
\text { SD }\end{array}$ & $\begin{array}{c}\text { Feasibility } \\
\text { Mean }\end{array}$ & $\begin{array}{c}\text { Feasibility } \\
\text { SD }\end{array}$ \\
\hline Social Bonds & Invest in Friends and Family & $13 c$ & 9.0 & 1.25 & 4.7 & 0.47 & 4.2 & 0.92 \\
\hline Social Bonds & Join a Club & $13 \mathrm{~g}$ & 8.5 & 1.51 & 4.1 & 1.04 & 4.3 & 0.67 \\
\hline Life Style & Be Active Both physically and mentally & $18 a$ & 8.4 & 1.19 & 4.5 & 0.52 & 3.8 & 1.04 \\
\hline Meaning & Practice Your Religion & $19 e$ & 8.2 & 1.39 & 4.0 & 0.89 & 4.0 & 0.87 \\
\hline Health Self Care & Get Physical Exercise & $15 b$ & 8.0 & 1.63 & 4.1 & 0.94 & 3.7 & 1.06 \\
\hline Social Bonds & Act Nicely & $13 d$ & 7.9 & 1.60 & 4.0 & 1.00 & 4.0 & 0.94 \\
\hline Meaning & Be Generous & $19 c$ & 7.9 & 1.37 & 4.2 & 0.87 & 3.8 & 1.03 \\
\hline Health Self Care & Check Your Health & $15 \mathrm{~d}$ & 7.9 & 1.17 & 3.8 & 0.87 & 3.8 & 0.67 \\
\hline Home Environment & Experience Nature & $14 \mathrm{e}$ & 7.8 & 1.40 & 3.7 & 1.10 & 4.1 & 0.57 \\
\hline Work & Socialize with Colleagues Outside of Work & $12 f$ & 7.8 & 1.55 & 3.7 & 0.79 & 4.0 & 0.94 \\
\hline Social Bonds & Focus on the Happiness of Others & $13 f$ & 7.8 & 1.87 & 4.2 & 0.98 & 3.6 & 1.07 \\
\hline Mental Development & Keep Learning & $16 a$ & 7.7 & 1.16 & 3.7 & 0.79 & 4.0 & 0.67 \\
\hline Meaning & Volunteer & $19 \mathrm{~d}$ & 7.7 & 1.57 & 4.3 & 0.65 & 3.4 & 1.17 \\
\hline Social Bonds & Marry & $13 a$ & 7.7 & 1.42 & 4.2 & 0.98 & 3.4 & 1.26 \\
\hline Meaning & Don't Seek Happiness & $19 a$ & 7.6 & 1.85 & 4.0 & 1.05 & 3.4 & 1.19 \\
\hline Life Style & Set Goals & $18 b$ & 7.6 & 1.13 & 4.1 & 0.54 & 3.4 & 0.73 \\
\hline Life Style & Enjoy & $18 \mathrm{c}$ & 7.6 & 1.13 & 4.0 & 0.63 & 3.6 & 0.73 \\
\hline Health Self Care & Get Regular and Ample Sleep & $15 c$ & 7.5 & 1.18 & 4.3 & 0.65 & 3.2 & 1.03 \\
\hline SA Financial & Enroll in Automatic Savings & $20 \mathrm{~b}$ & 7.5 & 2.07 & 3.8 & 1.04 & 3.8 & 1.04 \\
\hline Positive Outlook & Accept Yourself & $17 c$ & 7.4 & 1.67 & 4.5 & 0.69 & 3.0 & 1.22 \\
\hline Mental Development & Seek Challenges & $16 \mathrm{~b}$ & 7.3 & 1.73 & 3.8 & 0.75 & 3.4 & 1.01 \\
\hline SA Home Environment & Safe Surroundings & $20 n$ & 7.3 & 1.38 & 4.0 & 0.71 & 3.0 & 1.15 \\
\hline Positive Outlook & Laugh & $17 \mathrm{~b}$ & 7.3 & 2.28 & 3.7 & 1.37 & 3.7 & 1.10 \\
\hline Health Self Care & Invest in Good Health Insurance & $15 \mathrm{e}$ & 7.3 & 0.89 & 3.8 & 0.63 & 3.4 & 0.52 \\
\hline Life Style & Find a Way of Life That Fits You & $18 \mathrm{~d}$ & 7.3 & 1.67 & 4.1 & 1.04 & 2.9 & 1.13 \\
\hline Meaning & Seek Purpose & $19 b$ & 7.2 & 2.18 & 3.7 & 1.15 & 3.5 & 1.13 \\
\hline SA Positive Outlook & Keep a Gratitude Journal & $20 q$ & 7.1 & 1.29 & 3.3 & 1.01 & 3.9 & 0.57 \\
\hline SA Home Environment & Optimize Your Bedroom for Sleep & $20 \mathrm{k}$ & 7.0 & 1.41 & 3.3 & 1.11 & 3.7 & 0.52 \\
\hline Work & Avoid Long Commutes & $12 \mathrm{c}$ & 7.0 & 1.12 & 4.3 & 0.67 & 2.7 & 0.87 \\
\hline Financial & Keep Out of Debt & $11 \mathrm{~b}$ & 7.0 & 1.20 & 4.1 & & 3.1 & 0.93 \\
\hline Work & Seek a Job That Fits You & $12 a$ & 7.0 & 1.56 & 0.78 & & 2.7 & 1.06 \\
\hline Positive Outlook & Train to Have a Positive Outlook & $17 a$ & 6.9 & 2.21 & 0.79 & 1.45 & 3.5 & 1.04 \\
\hline Mental Development & Know Your Strengths & $16 \mathrm{c}$ & 6.9 & 1.62 & 3.6 & 1.03 & 3.3 & 0.71 \\
\hline Financial & Invest in Experiences & $11 \mathrm{~d}$ & 6.8 & 1.56 & 3.3 & 1.06 & 3.7 & 0.82 \\
\hline Home Environment & Opt for an Average House & $14 \mathrm{c}$ & 6.7 & 0.95 & 3.3 & 0.67 & 3.4 & 0.53 \\
\hline SA Positive Outlook & Write About Positive Experiences & $20 p$ & 6.7 & 1.34 & 3.0 & 1.00 & 3.8 & 0.79 \\
\hline SA Social Bonds & Add at Least One New Happy Person & $20 \mathrm{c}$ & 6.7 & 1.42 & 3.8 & 0.63 & 2.9 & 1.10 \\
\hline Home Environment & Choose to Live Near Family & $14 a$ & 6.6 & 1.00 & 3.8 & 0.75 & 2.8 & 0.39 \\
\hline SA Home Environment & Grow a Garden & $20 \mathrm{i}$ & 6.6 & 1.90 & 3.4 & 0.73 & 3.0 & 1.15 \\
\hline SA Home Environment & Live in an Environment of Trust & 201 & 6.5 & 2.00 & 4.3 & 1.12 & 2.3 & 1.04 \\
\hline Mental Development & Develop Skills for Happiness & $16 \mathrm{~d}$ & 6.5 & 2.16 & 3.4 & 1.24 & 3.1 & 0.94 \\
\hline Financial & Invest in Durables and Savings & $11 \mathrm{c}$ & 6.4 & 0.92 & 3.2 & 1.09 & 3.1 & 0.78 \\
\hline Work & Limit Your Work Hours & $12 b$ & 6.3 & 1.41 & 3.5 & 1.08 & 2.9 & 0.78 \\
\hline Social Bonds & Use/Learn Social Media & $13 e$ & 6.3 & 1.41 & 2.4 & 0.92 & 3.9 & 0.93 \\
\hline Health Self Care & Eat Healthy & $15 a$ & 6.3 & 1.68 & 2.9 & 1.08 & 3.3 & 0.79 \\
\hline SA Home Environment & Own a Pet & $20 \circ$ & 6.2 & 1.75 & 3.1 & 1.22 & 3.2 & 1.03 \\
\hline SA Life Style & Develop Arts Appreciation & $20 \mathrm{~s}$ & 6.1 & 2.19 & 3.1 & 1.05 & 3.1 & 1.21 \\
\hline SA Home Environment & Create a Meditation Space & $20 f$ & 6.1 & 1.45 & 3.3 & 1.12 & 2.8 & 1.09 \\
\hline Mental Development & Use Professional Advice & $16 \mathrm{e}$ & 6.1 & 1.22 & 3.1 & 1.00 & 3.2 & 0.87 \\
\hline Life Style & Monitor Your Happiness & $18 \mathrm{e}$ & 6.1 & 2.55 & 2.8 & 1.40 & 3.3 & 1.27 \\
\hline SA Meaning & Write a Personal Mission Statement & $20 \mathrm{v}$ & 6.0 & 1.67 & 3.7 & 1.15 & 3.6 & 1.13 \\
\hline SA Meaning & Create a Giving Account & $20 w$ & 5.9 & 1.66 & 2.6 & 1.07 & 3.3 & 0.82 \\
\hline SA Home Environment & Maximize Sunlight & $20 \mathrm{j}$ & 5.9 & 1.57 & 3.4 & 0.74 & 2.6 & 1.13 \\
\hline SA Social Bonds & Curate a Tight Social Circle (Moai) & $20 \mathrm{~d}$ & 5.7 & 1.50 & 3.3 & 0.89 & 2.6 & 0.79 \\
\hline Social Bonds & Have children & $13 b$ & 5.7 & 1.83 & 2.7 & 0.98 & 3.1 & 1.10 \\
\hline SA Life Style & De-Clutter & $20 u$ & 5.7 & 0.82 & 2.9 & 0.64 & 2.8 & 0.75 \\
\hline $\begin{array}{l}\text { Home Environment } \\
\text { SA Home Environment }\end{array}$ & $\begin{array}{l}\text { Own Your House } \\
\text { Designate a "Flow" Room }\end{array}$ & $\begin{array}{l}14 \mathrm{~d} \\
20 \mathrm{~g}\end{array}$ & $\begin{array}{l}5.5 \\
5.5\end{array}$ & $\begin{array}{l}1.31 \\
1.58\end{array}$ & $\begin{array}{l}2.6 \\
2.5\end{array}$ & $\begin{array}{l}1.07 \\
1.08\end{array}$ & $\begin{array}{l}2.9 \\
3.0\end{array}$ & $\begin{array}{l}0.33 \\
0.82\end{array}$ \\
\hline Home Environment & Choose Live in a Suburb or a Small Town & $14 \mathrm{~b}$ & 5.5 & 1.60 & 2.9 & 1.05 & 2.8 & 0.97 \\
\hline SA Financial & Minimize Credit Cards & $20 a$ & 5.4 & 2.01 & 2.8 & 1.40 & 2.7 & 1.25 \\
\hline SA Home Environment & Live in Quiet Surroundings & $20 \mathrm{~m}$ & 5.4 & 0.98 & 3.1 & 0.83 & 2.4 & 0.53 \\
\hline SA Life Style & Learn The Value of Your Free Time & $20 \mathrm{r}$ & 5.4 & 2.07 & 3.0 & 1.12 & 2.6 & 0.98 \\
\hline SA Home Environment & Eliminate Screens & $20 \mathrm{e}$ & 5.4 & 1.17 & 2.6 & 1.12 & 2.9 & 0.88 \\
\hline Financial & Build wealth & $11 \mathrm{a}$ & 5.3 & 1.35 & 2.8 & 0.94 & 2.4 & 0.81 \\
\hline SA Home Environment & Create a Pride Shrine & $20 \mathrm{~h}$ & 5.3 & 0.89 & 2.1 & 0.99 & 3.4 & 0.52 \\
\hline Work & Work Part-Time & $12 \mathrm{e}$ & 5.1 & 1.60 & 2.6 & 0.81 & 2.5 & 1.08 \\
\hline Work & Employ Yourself & $12 d$ & 5.1 & 1.81 & 2.6 & 1.36 & 2.5 & 0.67 \\
\hline SA Life Style & Become a Vegan & $20 \mathrm{t}$ & 3.9 & 1.35 & 1.5 & 0.93 & 2.3 & 0.71 \\
\hline Mean & & & 6.7 & 1.5 & 3.5 & 0.95 & 3.3 & 0.90 \\
\hline SD & & & 1.01 & 0.38 & 0.65 & 0.22 & 0.51 & 0.23 \\
\hline $\mathrm{SD}+$ & & & 7.72 & 1.90 & 4.14 & 1.17 & 3.76 & 1.13 \\
\hline SD - & & & 5.70 & 1.14 & 2.83 & 0.72 & 2.75 & 0.67 \\
\hline
\end{tabular}


Table 3 (continued)

An Excel file with more detail is available at: https://www.eur.nl/en/ehero/publications/working-paper s/2017-01

Using this file, you can sort the ratings in different ways

we considered the differences in the ratings, to determine on which strategies the experts agreed with most and which least, focusing on the standard deviations. Finally, we looked at the divergence between the ratings of effectiveness and feasibility, to determine which ways to greater happiness were deemed effective but not to be feasible and which feasible but not effective. This analysis was done by comparing findings across rows in the tables.

\subsection{Presentation}

All rankings are presented in Tables 2 and 3. The colors used in these tables are explained in Table 1.

Average ratings of effectiveness and feasibility are presented in shades of green, where darker shades denote higher scores. Differences in these ratings among experts are presented in shades of red, where darker red denotes more disagreement.

Links at the bottom of these tables lead to excel files that contain more detail, which readers can use to sort the ratings in different ways.

The numbers in the 3rd left columns of Tables 2 and 3, link to a row in Appendix G of the documentation, on which that particular strategy is described, as presented to the expert, together with the rationales advanced in first and second round.

In the next sections of this paper, the reader will see statements in the text that refer to a row in the Tables 2 or 3. Links can facilitate comparison of stated conclusions with observed ratings. Linking to row in a table is standard in pdf, but does not work in the pdf version currently used for this journal, which allows only a link to the top of the table. A fully functional pdf version is available online at: https://www.eur.nl/en/ehero/publications/working-paper s/2017-01.

\section{Results}

We will now focus on the combined ratings for effectiveness and feasibility of the strategies for greater happiness. We will not consider these matters separately. In this paper we discuss cost-effectiveness only shortly, since the ratings for this point were very similar to the general effectiveness ratings. We mark the main findings in in the Sects. 3.1.4 and 3.2.4. More detailed information is available in extended presentations of the ratings, a link to which is found at the bottom of the Tables 2 and 3.

The highest possible rating for summed effectiveness and feasibility of a strategy was 10 (average score of 5 on both) and the lowest possible rating was 2 (average 1 on both). We did not find any extreme scores, with summed ratings for effectiveness and feasibility ranging from 8.4 to 4.2. This means that our experts were not overenthusiastic; however, with an average score of 6.6 , we can assume that most of the proposed ways to greater happiness were deemed suitable.

Not all strategies were equally valued. Below we fist present the strategies deemed most effective and feasible and next review the strategies deemed least effective and feasible. In 
our presentation, we follow a slightly different categorization than presented in the tables, in order to present the same findings in another light.

\subsection{What Do Experts Think that Policymakers Can Do to Produce Greater Happiness for a Greater Number of Citizens?}

Together, the experts proposed 56 strategies for raising the level of happiness in a country. Their ratings of these strategies are presented in Table 2, both the average scores (M) of effectiveness and feasibility and the differences in these rating (SD).

As announced in Sect. 2.5, we will first consider the average ratings, focusing on the sum of effectiveness and feasibility (M), then the differences in ratings across experts (SD) and lastly the differences in ratings for effectiveness and feasibility.

\subsubsection{Average Ratings for Effectiveness and Feasibility}

Which of the 56 proposed strategies were judged to be the most apt, which the least? To answer this question, we need to focus on column 4 in Table 2 where degrees of summed effectiveness and feasibility are indicated, using different shades of green: the darker the green, the most apt.

\section{Most apt}

The following policy strategies were rated the most effective and feasible. Expert agreement was typically high on these approaches.

\section{Invest in happiness research}

Experts call for more happiness research, since this is required for evidence based policymaking and for overcoming ideological prepossession about ways to greater happiness. The experts call for three strands of research in particular: (a) looking for what works for whom, rather than focusing on an average citizen, (b) monitoring happiness over time, to assess progress and effectiveness of interventions and (c) assessing how much of the things deemed conducive for happiness is optimal; for example: How many years of their life should citizens spend sitting in their school desks, for the sake of greater happiness?

\section{Invest in good governance}

Experts emphasize the importance of institutional quality in a country and in particular quality of the civil services. Though few citizens will associate happiness with bureaucracy, well-functioning public organizations does add to the happiness of a great number of them. One of the reasons is that institutions, like courts and employment offices, create a predictable environment, in which citizens can plan their lives and are less dependent on pressures by kin and neighbors.

\section{Support vulnerable people}

Experts advise prioritizing strategies aimed at the least happy citizens in a nation. In this context, they recommend findings ways to: (a) to reduce loneliness and (b) to combat discrimination and (c) to provide free health care. In this context, several experts also mentioned (d) minimum income security (e) support of families, (f) reduction of 
unemployment, and (g) political empowerment, but the panel is more divided on these issues.

\section{Strengthen social bonds}

Experts mention several ways to improve the social climate in a nation and in particular recommend policies to (a) promote voluntary work and (b) increase support for non-profit organizations. Some of the experts recommend introduction of civil service. Further recommendations in this context rated average for effectiveness and feasibility are: (c) to facilitate social contacts, such as by providing (d) support for local fairs and festivals. The above-mentioned advice to support families also fits this context.

\section{Invest in health care}

The experts advise governments to provide (a) free health care, a strategy already mentioned above in the context of focusing on vulnerable people, (b) to prioritize prevention and in that context and (c) to encourage healthy living. Expert call for (d) investment in mental health care in particular and in that line also finding ways (e) to bring life-skills into schools and (f) foster people's ability to choose.

\section{Invest in education}

Experts agree largely that (a) investment in education is an effective and feasible way to greater happiness in a country, but they are less unanimous on whether (b) free education is required for that purpose. They are also less unanimous, but still positive, about particular investments, such (c) to bring life skills into the school curriculum (d) maintain order in schools, (e) monitor happiness in schools and (f) also support happiness education outside the school system.

\section{Support work}

Macro-economic strategies score not too high in the ratings, as we will see in more detail below, however most experts recommend (a) improvement of working conditions and (b) reduction of unemployment.

\section{Focus on economic stability}

With respect to macro-economic policy, the experts advise (a) an economic policy that favors stability over growth. Fostering economic growth is at the bottom of Table 2. Though experts recommend (b) providing minimum income security and (c) reducing unemployment (as mentioned above for supporting vulnerable people), the experts are less in favor of (d) reducing income inequality and (e) reducing working hours.

\section{Higher tax}

Most of the above recommendations will require higher tax rates. Experts deem that strategy effective, but not well feasible.

\section{Least apt}

Let us now look at the ways to greater happiness deemed less effective by the majority of the experts, presented in the lower part of Table 2. Since at least one expert has proposed all strategies, low average ratings typically go together with high difference of rating, the correlation between average and standard deviation is -.43. Note that a low score for effectiveness and feasibility does not mean that the proposed strategy will be counter-productive and lower average happiness in a nation; rather it means that the 'medicine' will not work. 
Combat capitalism and consumerism

Though market forces are often held responsible for unhappiness in modern societies (e.g. by Lane 2000), not all experts support all suggestions for taming these forces, such as (a) to counter-balance global capitalism. Experts also do not support (b) reduction of working hours and (c) stimulating consumption of stimulus-goods over comfort-goods. This is not to say that our panel embraces materialism, because they unanimously see some point in (d) favoring saving over consumption and expect little gain in (e) supporting home-ownership and (f) fostering economic growth. Above, we have also seen that the experts are positive about some correction of market forces, such as improving work conditions and providing minimum income security.

\section{Improve happiness advice and coaching}

Experts are skeptical about (a) fostering professional happiness coaching, typically fruits of the new 'positive psychology'. Still, we have seen above that they endorse (b) investment in mental health care and (c) bringing life-skills into the school curriculum.

\section{Support modernization}

Though people live happiest in the most modern societies, the panel is divided on whether backing spontaneous societal development (rather than slowing it down), will add to greater happiness in a country. The experts agree on a low rating for feasibility of this strategy.

\subsubsection{Agreement and Disagreement Among Experts About Policy Strategies}

How much consensus is there within the panel? On what strategies do the experts agree? On which do they diverge? Expert agreement is indicated by shades of red in Table 2.

\section{Agreement}

Experts agree most on: (a) reduce loneliness, (b) combat discrimination, (c) focus on the least happy and (d) empower and involve citizens. They also agree strongly on the lower effectiveness of (e) maintaining order in schools, (f) investing in a greener environment, (g) education of parents and $(\mathrm{h})$ reducing income inequality.

\section{Disagreement}

In their ratings of strategies policy makers can follow to raise the level of happiness in a country, experts differ most on the following economic strategies: (a) improving workconditions and (b) reduction of unemployment and (c) increasing foreign aid. Experts also differ in their ratings of the following issues in health policy: (d) prioritizing prevention, (e) encourage healthy living and (f) getting people to the dentist. Another point of disagreement is $(\mathrm{g})$ reduce use of cars and $(\mathrm{h})$ stimulate study abroad.

\subsubsection{Difference Between Effectiveness and Feasibility of Political Strategies}

Ways to greater happiness can be effective but not easily feasible, or well feasible, but not very effective. Do such differences occur in the ratings of our experts? Below we consider 
the differences of more than 1 point on the 1 to 5 ratings of effectiveness and feasibility of particular strategies. Note that the panel was selected for expertise in effectiveness in the first place and may not be equally acknowledged on practicability.

\section{Effective but not feasible}

Several macro-economic strategies are seen to be effective, but not feasible. These are: (a) favor economic stability over economic growth, (b) increase support for non-profits, (c) increase taxes and (d) reduce income inequality. A similar difference appears in the ratings of two psychological strategies: (e) foster ability to choose and (f) support happiness education. Likewise, experts deem effectiveness higher than feasibility for (g) promoting voluntary work, such as by civil service for every body and (h) empowering citizens and involving them in the political process. Surprisingly, the biggest difference (2 points), was on maintaining order in schools.

\section{Feasible but not effective}

Interestingly, none of the strategies policymakers can follow were deemed better feasible than effective.

\subsubsection{Cost-Effectiveness}

The macro strategies deemed most effective + feasible are also rated high for cost-effectiveness, that is, rated 4 or more. This is most apparent for (a) investment in happiness research, such as monitoring happiness in nations, findings out what works for whom and assessing how much of conditions for happiness is optimal in a nation. Likewise, (b) investments in social support are deemed cost-effective, in particular reducing loneliness and a policy focus on the least happy. Promoting (c) good governance is also rated high for cost-effectiveness.

None of the strategies that were rated effective + feasible (6.7 or more) was deemed to be cost-ineffective ( 3 or less) and none of the strategies in the lower half of Table 2 was rated cost-effective.

\subsection{What Do Experts Think That Individuals Can Do to Make Their Lives More Satisfying Life?}

Together, the experts proposed 68 strategies that individuals could follow to raise their own happiness. These options and the expert's ratings of these for effectiveness and feasibility are presented in Table 3. Again, we first summarize the strategies rated highest and next the ones rated lowest, we then consider unanimity among the experts and lastly the possible divergence between effectiveness and feasibility of the strategies.

\subsubsection{Average Ratings for Effectiveness and Feasibility of Individual Strategies}

Which of the individual strategies are reckoned to be the most apt? Which the least? Differences ratings are indicated using shades of green in the columns of Table 3

\section{Most apt}

The general strategies in the top of the table are rated higher than the more specific recommendations at the bottom. The main recommendations are as follows: 


\section{Connect}

Experts advise in the first place to focus social bonds, such as by (a) investing in friends and family, (b) joining a club, (c) acting nicely (d) marrying and (e) socialize with colleagues. They see more gain in social contact when (f) the focus is on the happiness of others and that advice fits the strategy recommended below.

\section{Seek meaning}

Experts think that living a meaningful life will make that life more satisfying. They recommend the following ways to seek meaning: (a) live up to your values, and if you are religious, practice your religion, (b) be generous and (c) volunteer, and (d) do not focus on your own happiness in the first place and (e) seek a purpose in life, which (f) you may clarify by writing a personal mission statement.

\section{Be active}

Experts agree that an active way of life is the most satisfying. They recommend in particular (a) getting regular physical exercise, (b) to keep learning and (c) to set goals and (d) to seek challenges. This advice goes counter to common notions of an easy happy life.

\section{Mind your health}

Alongside their advice to live an active life, experts also recommend (a) to get regular and ample sleep and some of them even endorse the recommendation (b) to optimize one's bedroom for good sleep. With respect to physical health experts advise (c) to check your health regularly and (d) to invest in a good health insurance. With respect to mental health, there is modest support for (f) use of professional advice, though mental health care figures prominently in the policy strategies reviewed above in Sect. 4.1. Still, some trainings for positive mental health are mentioned, such as cultivating a positive outlook on life, which we discuss below.

\section{Cultivate a positive outlook}

Several strategies are mentioned in this context. (a) Fostering self-acceptance is rated effective, but not easily feasible and experts disagree on the effectiveness of (b) to laugh often, (c) follow trainings that promote a positive outlook, (d) to keep a gratitude journal or (e) to write about positive experiences.

\section{Save}

Economic issues are again not very prominent in the rankings. The highest scores are for the advice to (a) enroll in automatic saving plans, (b) to avoid getting into debt and (c) to invest in durables and savings. Experts are less supportive of the advice (d) to minimize credit cards.

\section{Find a way of life that fits you}

Not very prominent either, is the more abstract advice to (a) find a lifestyle that fits you and in particular, (b) a job that fits you. This strategy requires you (c) to know your strengths and (d) to monitor your happiness, neither of which are seen as very effective or feasible.

\section{Least apt}

At the bottom of Table 3 are many strategies deemed ineffective or not feasible; most of these are rather specific recommendations. 


\section{Get rich}

Contrary to the common view that money buys happiness, experts do not advise (a) to build wealth, which is deemed ineffective and not very feasible for most individuals. The same holds for (b) own your house. These judgements do not fit too well with the abovementioned advice to save.

\section{Have children}

Raising a family is rated as feasible, but not as an effective way of raising one's own happiness. Owning a pet is deemed slightly more effective, though experts diverge on that matter. Experts do endorse the advice to live close to family, though they deem this not easily done.

\section{Reduce workload}

In spite of considerable publicity about work-stress and related burnout (e.g. Schor 1991) experts do not whole-heartedly endorse the advice to (a) limit your working hours, and see no point at all in (b) work part-time. They see more effect in (c) avoiding a long commute, but rate the feasibility of that option as low for most individuals.

\section{Choose for an alternative life-style}

Several of the lowest rated strategies are part of unconventional ways of life, inspired by anti-materialism, new-age thinking, environmental concern and food-awareness, such as: (a) de-clutter, (b) eliminate screens in your house, (c) designate a 'flow' room, (d) create a meditation space and (e) become a vegan. As noted in Sect. 2.4, these strategies were part of a set of optional questions on specific behaviors, which we added in the last round. One of the reasons for the low scores is probably, that there is little research on these matters, and probably for that reason, several experts skipped these optional questions.

\subsubsection{Agreement and Disagreement Among Experts About Individual Strategies}

What can we say about consensus in the panel on ways in which individuals can make their life more satisfying? Differences in expert agreement are indicated using shades of red in Table 3. The darker the red, the less agreement.

\section{Agreement}

Experts agree the most on high effectiveness of (a) investment in family and friends, (b) leading an active life, such as by (c) setting goals and (d) volunteering. Experts also agree on the importance of: (e) being open for enjoyments, (f) good sleep and (g) self-acceptance. They also agree in low ratings for (h) opting for an average house and (i) de-cluttering.

\section{Disagreement}

Experts disagree most on the recommendations inspired by positive psychology, such as (a) laugh, (b) train to have a positive outlook, (c) develop skills required for greater happiness and (d) monitor your happiness. They also disagree (e) on the effectiveness of selfemployment for leading a happier life. 


\subsubsection{Difference Between Effectiveness and Feasibility of Individual Strategies}

The following ratings of effectiveness and feasibility differed more than 1 point on scale 1-5. Remember that the panel was selected for expertise in effectiveness in the first place.

\section{Effective but not feasible}

The experts rate effectiveness of the following psychological strategies higher than their feasibility: (a) accept yourself, (b) seek a job that fits you and (c) find a way of life that fits you. A similar difference appears in the ratings of two more tangible strategies: (d) keep out of debt and (e) avoid long commutes. The greatest difference in effectiveness and feasibility is seen in (f) live in an environment of trust.

\section{Feasible but not effective}

The experts rate practicability higher than effectiveness for (a) use/learn social media and (b) create a 'pride shrine' in your house. In both cases, the difference is due to a low effectiveness rating.

\subsubsection{Cost-Effectiveness of Individual Strategies}

The individual strategies rated highest for effectiveness + feasibility are also rated highest for cost-effectiveness, that is 4 points or more. This concerns building social bonds, such as by investing in friends and family, joining clubs and focusing on the happiness of others. Likewise, life-style matters rated high for cost-effectiveness are: be active, experience nature and get exercise.

Only one of the individual strategies deemed effective and feasible, was rated cost-ineffective, that is below 3 . This was investing in experiences. None of the strategies rated lower than 6.7 for effectiveness + feasibility was considered cost-effective.

\section{Discussion}

Above, we summarized the experts' responses, focusing on strategies deemed both effective and feasible. Let us now take a helicopter view of the results. Below, we will first consider the differences between the view taken by experts and prevailing public opinion on ways to greater happiness. We then dwell on the difference in views among experts; we set out to establish consensus but find much disagreement. Next, we consider possible ideological bias in the expert ratings; could their reading of facts be influenced by their political preferences? Lastly, we propose an agenda for further synthetic research on ways to greater happiness.

\subsection{Differences with Common Views on Ways to Greater Happiness}

The results of this study will not surprise most of our colleague researchers, since they reflect the current state of the art. Still, some may have expected greater consensus than appears from the ratings. There will be more news for lay people, since many of the recommendations made by the experts are absent in public opinion polls on perceived sources of happiness. 


\subsubsection{Discrepancy in Expert-Lay View on Ways to Raise Happiness in the Nation}

Studies on perceived sources of happiness in the general public are listed in the Bibliography of Happiness (Veenhoven 2017c), in the subject section 'Views on happiness in public opinion'.

We acknowledged this literature in the comments below.

Expert's views fit common sense with respect to (a) reducing unemployment, (b) creating a supportive social climate and (c) providing minimum income security, (d) free health care and free education and (e) investing in clean air.

A surprise may be in the high rating of (f) good governance, the functioning of bureaucracy in particular, though corruption figures in some polls as a source of unhappiness. Lay people may not expect that experts rate (f) more happiness research highest, as they will think that experts know everything already.

Things mentioned by the experts, that may not be expected by the public are; (g) increased taxes, (h) prioritize mental health care and (i) bringing life skills into schools.

Lay-people may be surprised to see that experts disagree so much in their effectiveness ratings of $(\mathrm{j})$ improving work conditions, $(\mathrm{k})$ reducing unemployment and (l) prioritize preventive healthcare, in particular $(\mathrm{m})$ healthy living.

\subsubsection{Discrepancy in Expert-Lay Views on Ways to Greater Happiness for One-Self}

Studies on perceived sources of one's own happiness i are listed in the Bibliography of Happiness (Veenhoven 2017c), in the subject section 'Views on one's own happiness'. What are the similarities and differences with the expert's recommendations?

The expert recommendations fit public opinion with respect to importance of (a) social bonds, family in particular, (b) an active life-style and (c) a green home environment. Expert's ratings also fit lay-people's majority view that (c) building wealth is not required for a happy life.

Expert's ratings also fit common-sense view that no greater happiness is to be expected from following trendy alternative life-style advice, such as (d) eliminate screens, (e) create a flow-room in your house or (f) become a vegan. Likewise, lay-people may be equally skeptical about the effectiveness of psychological training as most of the experts are.

The expert's opinion that ( $\mathrm{g}$ ) children do not add to happiness, differs from the dominant view in public opinion, though this counter-intuitive finding has received much attention in the media. There is no strong public opinion on the effect on happiness of (h) self-employment, but lay-people will be surprised to see that experts differ so much on this issue.

\subsection{Why Not More Agreement?}

The prime aim of this study was to assess scientific consensus on ways to greater happiness. We found considerable agreement among our experts, but also much disagreement, as can be seen from the many red colored cells in Tables 2 and 3. Why is there so much disagreement among experts?

One reason is in the maturity of this research field. Happiness research is new, taking off in the 1990s, and many issues have not yet had sufficient research for the answers to become crystallized. This is why reviewers disagree so often (cf. Sect. 1) and why, for getting an overview, we resorted to the Delphi method. 
Another reason may be found in disciplinary differences in our panel of experts, in particular between economists and psychologists, each drawing on a somewhat different research literature. The divergence in effectiveness ratings for life-coaching and psychological exercises may results from this.

One more reason lies in the questions we presented the experts. We asked them for ways to greater happiness that apply for all countries and all individuals, that is, one-size-fits-all recommendations. We did so, because we wanted to grasp consensus about universal conditions. Yet, in reality, conditions for happiness differ considerably between and within countries.

\subsection{Leftish Bias?}

Some of the strategies endorsed by the experts fit a left wing socialist-political agenda, such as (a) free health care and free education, (b) minimum income security, (c) increased taxes and (d) favor economic stability over growth. Yet experts do not cherish all leftish ideas, given their low ratings for (e) reduction of income inequality and (f) counter-balancing global capitalism. In their rating of individual strategies, the experts also do not endorse less work or lavish spending. Note that experts were asked to judge ways to greater happiness based on their scientific knowledge, not to present their ideological preferences.

\subsection{Future Research}

This study reflects the views of leading experts on happiness at this moment. Since much progress is made in this research field, it would be interesting to repeat this study every 10 years.

A possible addition can be, to run parallel studies among policy-makers, practitioners in the field of life-coaching and the public. This would provide us a better view on the difference between current beliefs about ways to greater happiness and established facts on that matter.

\section{Conclusions}

There is considerable expert consensus on some ways in which policy makers can raise the level of happiness in a country, in particular to (a) invest in more happiness research, (b) to strengthen social bonds, (c) to promote good governance, and (d) to invest in education. They also agree on the ineffectiveness of several common strategies, among which (e) fostering economic growth.

Likewise, experts agree that ways individuals can follow to raise their own happiness are; (a) invest in your social bonds, (b) keep learning and (c) lead an active life. Experts also agree on the ineffectiveness of several trendy alternative ways of life.

There is also a lot of disagreement in our panel of experts in empirical happiness research and it is a task for further research to get a better view on the suitability of the various ways to greater happiness. 


\section{Electronic supplementary materials}

\section{Ways to Greater Happiness: A Delphy Study}

EHERO working paper 2017-01, Erasmus University Rotterdam, Netherlands, Erasmus Happiness Economics Research Organization, Available at: https://www.eur.nl/en/ ehero/publications/working-papers/2017-01.

Same text but in a pdf-version that provides links from statements in the text to rows in tables, which is not possible in the pdf version currently used for this journal. This working paper also provides links to further supplementary materials.

Open Access This article is licensed under a Creative Commons Attribution 4.0 International License, which permits use, sharing, adaptation, distribution and reproduction in any medium or format, as long as you give appropriate credit to the original author(s) and the source, provide a link to the Creative Commons licence, and indicate if changes were made. The images or other third party material in this article are included in the article's Creative Commons licence, unless indicated otherwise in a credit line to the material. If material is not included in the article's Creative Commons licence and your intended use is not permitted by statutory regulation or exceeds the permitted use, you will need to obtain permission directly from the copyright holder. To view a copy of this licence, visit http://creativecommons.org/licenses/by/4.0/http:// creativecommons.org/licenses/by/4.0/.

\section{References}

Adler, M. D., Dolan, P., \& Kavetsos, G. (2015). Would you choose to be happy? Trade-offs between happiness and the other dimensions of life in a large population survey. Duke Law School Public Law \& Legal Theory Series No. 2015-35. http://dx.doi.org/10.2139/ssrn.2640117.

Bentham, J. (1789). An introduction to the principles of morals and legislation, London. http://socserv2. socsci.mcmaster.ca/econ/ugcm/3113/bentham/morals.pdf.

Diener, E., Suh, E. M., Smith, H., \& Shio, L. (1995). National differences in reported subjective wellbeing: Why do they occur? Social Indicators Research, 34, 7-32.

Lane, R. E. R. E. (2000). The Loss of Happiness in Market Democracies. USA: Yale University Press.

Schor, J. (1991). The overworked American. USA: Basic Books.

Veenhoven, R. (2015). Happiness: History of the concept. In J. Wright (Ed.), International encyclopaedia of social and behavioural sciences (2nd ed., Vol. 10, pp. 521-525). Oxford: Elsevier.

Veenhoven. R. (2017a). World database of happiness: Archive of research findings on the subjective enjoyment of one's life as-a-whole. Erasmus University Rotterdam, Netherlands. https://worlddatab aseofhappiness.eur.nl. Accessed 1 June 2016.

Veenhoven, R. (2017b). Directory of happiness investigators. World Database of Happiness, Erasmus University Rotterdam. http://worlddatabaseofhappiness.eur.nl/directory.htm. Accessed 1 June 2016.

Veenhoven, R. (2017c). Bibliography of happiness. World Database of Happiness, Erasmus University Rotterdam. http://worlddatabaseofhappiness.eur.nl/hap_bib/bib_fp.php. Accessed 1 June 2016.

Publisher's Note Springer Nature remains neutral with regard to jurisdictional claims in published maps and institutional affiliations. 